\title{
PROLEGÔMENOS À CRÍTICA DO IMPERIALISMO GLOBAL
}

Flávio Bezerra de Farias

Universidade Federal do Maranhão (UFMA)

\section{PROLEGÔMENOS À CRÍTICA DO IMPERIALISMO GLOBAL}

Resumo: O texto trata da passagem da crítica da economia política para a crítica do imperialismo global. Isso envolve questões de Estado e capital, sociedade e história, virtualidade e realidade, práxis e transformação.

Palavras-chave: Imperialismo global, economia política, marxismo.

\section{PRELIMINARIES TO THE GLOBAL IMPERIALISM CRITIC}

Abstract: The text is about the passage of the critique of political economy to the critique of global imperialism. This involves questions of State and capital, society and history, virtuality and reality, praxis and transformation.

Key words: Global imperialism, political economy, marxism. 
1 INTRODUÇÃO: do capital ao estado

Como categoria genérica, originária e referida explicitamente à herança crítica e revolucionária (MARX, 1976), o marxismo merece ser distinto do socialismo superficial, que incorpora de modo eclético as abordagens estruturalistas e positivistas da sociedade, centrado na soma naturalizada da economia capitalista e da democracia burguesa formal, e reduz a luta emancipatória a um ideal ético, sobretudo de bem-estar social dentro da ordem, ou uma via parlamentar, progressiva e pacífica ao socialismo, sem luta de classes, como em muitas e diversas teorias da regulação (FARIAS, 2000) ou do agir comunicacional (FARIAS, 2001).

Com efeito, a mediação (ignorada pelos autores funcionalistas ou estruturalo-marxistas) é uma categoria social e histórica cuja forma ideológica fenomênica é a regulação (governança), que se situa, então, no tempo e no espaço. Do mesmo modo que não se deve julgar uma pessoa pelo que ela diz dela mesma, a mediação no seio dos fenômenos objetivos contraditórios não é o mesmo que a regulação (governança) como posição política e ideológica que se exprime subjetivamente por palavras, desejos e vontades. Portanto, as formas da superestrutura não asseguram de fato, como afirmam Hardt e Negri (2000, p. 313), uma regulação (governança) global por meio da "[...] aplicação efetiva da gestão e da autoridade capitalistas" sobre os aspectos contraditórios para impor uma unidade sem luta, no seio do mercado mundial por inteiro, que tenderia a ser o único coerente. No império realmente existente, para além da regulação multilateral garantida por um soft power, a nova doutrina totalitária posta em prática pelos falcões estadunidenses se baseia em três normas da regulação unilateral exercida por um hard power, a saber: a ação armada preventiva, a destruição dos regimes considerados como ameaçadores e a afirmação da preeminência dos EUA (DUMÉNIL; CASSEN, 2004, p. 45).

$\mathrm{Na}$ hipótese da aplicação atual da ideia geral de formação socioeconômica (MARX, 1977) à escala global, advém, desde logo, a constatação de que os interesses dominantes na nova ordem mundial convocam seus ideólogos, desde o fim da guerra fria, para carregar o pesado fardo ideológico que reside em elaborar a forma política de um novo império liberal, inclusive do Império sem frases; ao mesmo tempo em que a infraestrutura evolui mais rapidamente do que a superestrutura que Ihe corresponde, e, portanto, [...] "sob um mesmo diapasão." (BLOCH, 1981, p. 167). Como cada constelação (liberal, social, neoliberal, etc.) constitui [...]"o pressuposto de uma nova extensão cujo eco e porte excedem e se estendem por intermédio da série" das constelações, "estamos, então, diante de ressonâncias que constituem, por um lado, os períodos e, por outro, ainda que diferentemente, as esferas, graças à manutenção entre eles de um elemento comum", enquanto elementos de uma totalização concreta, complexa e contraditória (BLOCH, 1981).

Nas condições espaço-temporais da especificação histórica (KORSCH, 1971, 1976, 1979) do todo concreto formado por Estado e capital na escala global,

[...]"esse estado atual se nos representa, certamente, no mais alto imediatismo, mas também no culminar de uma longa evolução; é, portanto, nada mais do que um começo." (BLOCH, 1981, p. 169).

Em suma, somente

[...] "a ideia de historicidade concretamente universal das categorias de todo ser pode indicar a via que leva à visão justa, ao mesmo tempo unitária e historicamente diferenciada de maneira rigorosa." (LUKÁCS, 2009, p. 74).

Em compensação, o império isolado por abstração logicista e encontrado precipitadamente na época passada torna-se um mito pacificador, disponível para a operação contemplativa e conveniente ao interesse estreito de classe, que ignora a articulação entre as forças objetivas e subjetivas da história, que é incapaz de apreender no presente as tendências de uma mediação imperialista realmente existente, que fascinado pelas possibilidades objetivas-reais cai, enfim, no [...]"fetichismo do pensamento reificado, que só se sente, realmente, em segurança no passado acabado". (BLOCH, 1981, p. 18) da era imperial. Trata-se dos tempos pós-modernos e não da finalização do [...] "capitalismo dos tempos modernos, que marca para Marx a passagem da história anterior, resumida pelo termo pré-história, à sociedade sem classes." Antes que a pósmodernidade tivesse eliminado abstratamente a luta de classes para o evento fictício do fim da história, ao contrário da posição de Rosa Luxemburgo (1904, P. 172)

[...] muitos socialdemocratas avaliam terem experimentado um grande senso do concreto quando renunciaram, cada vez mais, aos princípios enunciados outrora por Bebel e Liebknecht segundo os quais mais vale cinquenta revoluções falhadas, mas pelo menos tentadas, do que nenhuma [...] Enfim, aparece a seriedade do princípio, o primeiríssimo sentido da palavra princípio: o do começo em toda a sua força.

$\mathrm{Na}$ herança socialdemocrata atual, existem muitas abordagens discordantes buscando chegar por diversas vias ao princípio imperial, cosmopolita 
ou transnacional de constituição de uma forma estatal global, em articulação com os fenômenos do contexto situado para além do fordismo e na era da globalização do capital. Quando, na realidade, longe de ser o produto final, harmonioso, encerrado e definitivo de um sistema fechado, tudo aquilo não passa de uma tendência conflituosa, aberta e transitória numa situação historicamente determinada. Portanto, [...] "a verdadeira divisa que preside à construção de nosso mundo e de nosso tempo, ou fervilha a experimentação do novo", em vez de seguir a lógica liberal enquanto "sobrevivência dos tempos idos, idolatrando a ordo simpiternus rerum [...]", muito antes pelo contrário "[...] é marcada pelo carimbo da coerência e, a este título, é a abertura sobre o não-ainda, é sistema aberto." (BLOCH, p. 26-27). Nessa via, existe a questão estratégica da relação entre a tomada do poder e a mudança do mundo, a saber: "Qual é a atitude a ser tomada nas condições do capitalismo global? E como evitar a gangrena burocrática que arruinou internamente as tentativas de emancipação passadas?" (BENSAÏD, 2008, p. 9).

Nessa perspectiva, é preciso que o "[...] questionamento se vincule a uma hipótese, a qual não traz ainda no seu bojo uma resposta decisiva, mas atribui um objetivo à questão[...]", ao mesmo tempo em que desenvolve "[...] as possibilidades de uma demonstração [...]", através de um procedimento no qual "[...] nem a experimentação nem o modelo devem, no entanto, serem compreendidos num sentido estreitamente positivista." (BENSAID, 2008, p. 232). Portanto, uma afirmação a priori torna-se uma hipótese, mas não um método, cujo objeto reduz o sujeito que assevera à passividade acrítica e positivista, "[...] seu único objetivo é de fazer entrar os eventos, as pessoas ou os atos considerados em moldes pré-fabricados." (SARTRE, 2005, p. 39). Um método apriorístico "[...] não tira seus conceitos da experiência - ou, pelo menos, não da experiência nova que busca decifrar -, ele já lhes formou, já está certo de sua verdade, Ihes atribuirá o papel de esquemas constitutivos." (SARTRE, 2005, p. 39).

É preciso, também, "[...] um pensamento categorial exato", porque "o conceito é o estadomaior da transformação e do advento possível, evitando que este último intervenha em um lugar diverso do que pretende o objetivo do Justo." $(\mathrm{BLOCH}, 1981$, p. 230). Em se tratando de ultrapassar todas as situações planetárias onde o homem é explorado, dominado e humilhado, em vez de se atribuir voluntariamente "a incapacidade quase total", própria às abordagens pós-modernas ou liberais do fim da história, "[...]de apreender atualmente o valor universal dos eventos históricos de porte mundial [...]", mais vale "se introduzir no seio dos próprios eventos[...]" e, de maneira crítica e engajada na transformação, "[...] penetrando-Ihes o sentido, esclarecendo-lhes a cada instante, do ponto de vista do processo e na sua totalidade, como uma forma das relações entre os homens." (BLOCH, 1981, p. 22).

Figura 1 - Silogismo

\begin{tabular}{|c|c|c|c|c|}
\hline \multicolumn{2}{|c|}{$\begin{array}{l}\text { Pequenos silogismos } \\
\text { da produção mercantil }\end{array}$} & \multicolumn{3}{|c|}{$\begin{array}{l}\text { Grande silogismo } \\
\text { do capital social total }\end{array}$} \\
\hline Simples & $\begin{array}{l}\text { Desenvolvida: } \\
\text { Reprodução de } \mathrm{P}\end{array}$ & $\begin{array}{l}\text { Ciclo do capital- } \\
\text { dinheiro }\end{array}$ & $\begin{array}{l}\text { Ciclo do capital- } \\
\text { mercadoria }\end{array}$ & $\begin{array}{l}\text { Ciclo do capital } \\
\text { produtivo }\end{array}$ \\
\hline $\begin{array}{c}\text { Pequeno silogismo } \\
\text { M-D-M: } \\
\text { As mercadorias } \\
\text { singulares, no } \\
\text { quadro particular } \\
\text { das trocas, levam } \\
\text { ao dinheiro, } \\
\text { a mercadoria } \\
\text { universal }\end{array}$ & $\begin{array}{l}\text { Num espaço } \\
\text { socialmente } \\
\text { homogêneo, } \\
\text { universal, a } \\
\text { subsistência do } \\
\text { assalariado e } \\
\text { a mais-valia do } \\
\text { capitalista ocorrem } \\
\text { em diferentes } \\
\text { molinetes, } \\
\text { singulares, } \\
\text { articulados } \\
\text { hierarquicamente } \\
\text { numa produção } \\
\text { mercantil particular }\end{array}$ & $\begin{array}{l}\text { Pequeno silogismo } \\
\text { D-P-M: } \\
\text { O universal (valor- } \\
\text { capital dinheiro } \\
\text { avançado) torna- } \\
\text { se particular } \\
\text { (mercadoria com } \\
\text { mais-valia), através } \\
\text { do singular (capital } \\
\text { produtivo individual) }\end{array}$ & $\begin{array}{l}\text { Pequeno silogismo } \\
\text { M-D-P: } \\
\text { A mercadoria } \\
\text { (com mais- } \\
\text { valia) particular } \\
\text { se transforma } \\
\text { em singular } \\
\text { (capital produtivo } \\
\text { individual), através } \\
\text { do universal (valor- } \\
\text { capital dinheiro } \\
\text { aumentado) }\end{array}$ & $\begin{array}{c}\text { Pequeno silogismo } \\
\text { P-M-D: } \\
\text { O singular } \\
\text { (capital produtivo } \\
\text { individual) produz } \\
\text { uma mercadoria } \\
\text { com mais-valia } \\
\text { particular, que se } \\
\text { transforma num } \\
\text { universal (valor- } \\
\text { capital dinheiro } \\
\text { aumentado) }\end{array}$ \\
\hline \multirow{3}{*}{$\begin{array}{c}\text { Contradições } \\
\text { mediadas } \\
\text { pelo dinheiro } \\
\text { (possibilidade geral } \\
\text { de crise) }\end{array}$} & \multirow{3}{*}{$\begin{array}{c}\text { Contradições } \\
\text { mediadas pelo } \\
\text { salário } \\
\text { (vicissitude } \\
\text { correlativa de crise) }\end{array}$} & Capital financeiro & Capital comercial & Capital industrial \\
\hline & & \multicolumn{3}{|c|}{$\begin{array}{l}\text { Rotação do capital social total } \\
\text { (base material de crise) }\end{array}$} \\
\hline & & \multicolumn{3}{|c|}{$\begin{array}{l}\text { Reprodução do capital social total } \\
\text { (lugar de manifestação de crise) }\end{array}$} \\
\hline
\end{tabular}

Fonte: Flávio Farias, a partir da crítica da economia política (MARX, 1976a). 
A extinção do modo e, portanto, das formas estatais capitalistas globais, não pode se produzir sem ruptura com as condições de divisão capitalista do trabalho que servem de eixo objetivo para a permanência das lutas de classes na escala mundial.
A crítica da economia política é uma premissa da crítica do modo estatal global, especialmente por sua teoria da totalidade concreta, movida pela luta de classes (Ver figuras 1 e 2).

Figura 2 - Pluralidade do capital industrial

\begin{tabular}{|c|c|c|c|}
\hline \multicolumn{4}{|c|}{ Grande silogismo historicamente determinado } \\
\hline \multicolumn{4}{|c|}{$\begin{array}{l}\text { Momento dialético inicial (homogeneidade): As leis da equalização e da queda da taxa de lucro, } \\
\text { enquanto tendências fundamentais da concorrência entre capitais produtivos } \\
\text { (causa imediata de crise) }\end{array}$} \\
\hline \multicolumn{4}{|c|}{$\begin{array}{l}\text { Momento dialético central (diferenciação): A Configuração do capital industrial, } \\
\text { enquanto formação quantitativa e qualitativa do capital e da classe dos capitalistas } \\
\text { (razão última de crise) }\end{array}$} \\
\hline Capital produtivo & \multicolumn{3}{|c|}{ Capital improdutivo } \\
\hline \multicolumn{2}{|c|}{ Capital-função } & \multicolumn{2}{|c|}{ Capital-propriedade } \\
\hline \multicolumn{2}{|c|}{ Capital ativo } & \multicolumn{2}{|c|}{ Capital inativo } \\
\hline \multicolumn{2}{|c|}{ Capital engajado } & \multicolumn{2}{|c|}{ Capital entrincheirado } \\
\hline \multicolumn{2}{|c|}{ Capital em ato } & \multicolumn{2}{|c|}{ Capital em potência } \\
\hline \multicolumn{2}{|c|}{ Capital real } & \multicolumn{2}{|c|}{ Capital-fetiche (moneyed capital) $\rightarrow$} \\
\hline \multirow{2}{*}{ Capital industrial } & Capital comercial & Capital financeiro & Capital fictício $\rightarrow$ \\
\hline & \multicolumn{2}{|c|}{ Capital mercantil } & Capital fundiário \\
\hline \multicolumn{4}{|c|}{ Lucro bruto: Produção pela produção } \\
\hline Lucro industrial & Lucro comercial & \multirow[t]{2}{*}{ Juro } & \multirow[t]{2}{*}{ Renda fundiária } \\
\hline \multicolumn{2}{|c|}{ Lucro de empresa } & & \\
\hline \multicolumn{3}{|c|}{ Capital (Lucro de empresa + Juro) } & Terra (Renda) \\
\hline \multicolumn{4}{|c|}{ Trabalho (Salário): Reduzida demanda solvável das massas } \\
\hline \multicolumn{4}{|c|}{$\begin{array}{l}\text { Momento dialético final (hierarquização): As classes sociais. } \\
\text { Terra-Trabalho-Capital reificados como fonte de rendimentos das classes sociais. } \\
\text { Fórmula trinitária que engloba todos os mistérios do processo social de produção. }\end{array}$} \\
\hline
\end{tabular}

Fonte: Flávio Farias, a partir da crítica da economia política (MARX; ENGELS 1976).

Conforme as figuras acima, o movimento cíclico do capital social total forma um grande silogismo, com três pequenos silogismos, a saber: os ciclos do capital-dinheiro (generalidade), do capital-mercadoria (particularidade) e do capital produtivo (singularidade); por sua vez, a pluralidade do capital industrial constitui um grande silogismo historicamente determinado (MARX, 1976).

Trata-se de aplicar, mais uma vez, a teoria marxiana da totalidade concreta ao domínio do Estado capitalista (FARIAS, 2000; 2001; 2004; 2013a,b), enquanto parte da formação socioeconômica global; porque "[...] o sujeito (indivíduo, consciência individual, espírito ou coletividade) deve efetuar uma peregrinação através do mundo para conhecer o mundo e a si mesmo." (KOSIK, 1978, p. 126). Portanto, "[...] para o marxismo, a teoria é o estadomaior da revolução e ela permanece assim por tanto tempo quanto a revolução política se revele necessária." (BLOCH, 1981, p. 245). A constelação da nova ordem mundial atual indica que isso continua válido por muito tempo; assim, na longa duração, "[...]o sucesso prático é, entretanto, não somente a última prova da exatidão da teoria revolucionária, como também e, sobretudo, o abrir caminho de um ato radicalmente [...]" distinto de uma abordagem superficial e fetichista, "[...]que permaneceria exclusivamente contemplativa." (BLOCH, 1981, p. 245).
Mesmo se as abordagens críticas mais radicais sublinham a organicidade e o movimento atinente ao Estado e ao capital na escala planetária, em geral "[...] os pensamentos mais avançados estão ainda prisioneiros, atualmente, de seu ambiente burguês ou de um ambiente socialista, ao certo, insuficientemente desenvolvido." (BLOCH, 1981 , p. 22). Assim, considere-se a categoria do império para ver que ela traz o carimbo de suas origens antigas, feudais, burguesas e socialistas realmente existentes, e que a teoria do império "[...] permanece uma pura contemplação, prisioneira dos clichés e dos preconceitos burgueses, estranha ao verdadeiro curso, ao presente autêntico da vida." (BLOCH, 1981, p. 20-21). Assim, no contexto do despertar político mundial,

[...] pela primeira vez na história, quase toda a humanidade está politicamente ativa, politicamente consciente, e politicamente interativa. $O$ ativismo mundial gera um aumento da busca do respeito cultural e da oportunidade econômica num mundo marcado pelas lembranças da dominação colonial ou imperial. (BRZEZINSKY, 2008, p. 1).

Com certeza, é decisivo ultrapassar os "[...] obstáculos elevados pelas sequelas da era do senhor 
e do escravo; porque vivemos somente uma época de transição, vivemos ainda em plena transição." (BLOCH, 1981, p. 23). É necessário insistir que se trata de uma transição cuja implantação é de longa duração. Supondo que depois dos Trinta Gloriosos do fordismo (1945-1975) persiste uma crise estrutural, cuja crise específica atual é nada mais do que sua última versão, é fácil constatar, nesse momento da ideologia do novo século americano, que as sociedades atuais

[...] atravessaram uma época historicamente muito próxima da gente e que foi, para o capitalismo, um período de expansão revolucionária; e, quando uma cultura atinge seu apogeu, se existe incontestavelmente uma fase de equilíbrio aparente, ela dura até o momento no qual a decadência somente permite perceber na ideologia apenas uma impostura e exclui a ideia de uma máscara cultural na qual acreditariam ainda os dominantes. Assim fazendo, essa fase de decadência que rasga o véu clássico das formações culturais pode provocar o aparecimento, em plena derrocada e pelo fato mesmo dessa derrocada, algo que pode se apresentar com traços grotescos, absurdos, expressionistas, surrealistas, como uma estranha aurora se elevando em pleno crepúsculo, pelo próprio fato desse crepúsculo. (BLOCH, 1981, p. 2324).

Figura 3 - Grande silogismo do modo estatal global

\begin{tabular}{|c|c|c|}
\hline Universal & Particular & Singular \\
\hline Forma estatal planetária & Formas estatais regionais & Formas estatais nacionais \\
\hline Coletiva ideal & $\begin{array}{l}\text { - Hegemônica central } \\
\text { - Sub-hegemônica central } \\
\text { - Sub-hegemônica periférica }\end{array}$ & $\begin{array}{l}\text { - Hegemônica central } \\
\text { - Sub-hegemônica central } \\
\text { - Sub-hegemônica periférica }\end{array}$ \\
\hline Pequeno silogismo 1 & Pequeno silogismo 2 & Pequeno silogismo 3 \\
\hline
\end{tabular}

Fonte: Farias (2013a).

Neste momento de grande transformação social e histórica, sabendo que "[...] a grande noite não é ainda para hoje e que os crepúsculos não chegam numa data fixa." (p. 27), enquanto que "[...] o capitalismo senil e o novo caos mundial [...]" (AMIN, 2001, p. 101) se prestam para todo tipo de contemplação e de utopia abstrata, torna-se útil, pois, agrupar numa totalidade concreta a riqueza das determinações percebidas no quadro "[...] de uma lógica material, particularmente sensível para com os vínculos mantidos entre os princípios lógicos e as categorias reais do processo." (BLOCH, 1981, p. 234). Na ótica da categoria central nomeada princípio, isto é, do princípio da esperança que quer

Figura 4 - Grande silogismo do modo imperialista global

\begin{tabular}{|c|l|l|}
\hline Universal & \multicolumn{1}{|c|}{ Particular } & \multicolumn{1}{c|}{ Singular } \\
\hline Hiperpotência planetária & \multicolumn{1}{|c|}{ Superpotências regionais } & \multicolumn{1}{c|}{ Potências nacionais } \\
\hline Imperialismo coletivo ideal & $\begin{array}{l}\text { - Imperialismo hegemônico central } \\
\text { norte-americano } \\
\text { - Subimperialismo central europeu } \\
\text { - Subimperialismo periférico sul- } \\
\text { americano }\end{array}$ & $\begin{array}{l}\text { • Imperialismo estadunidense } \\
\text { - Subimperialismo francês } \\
\text { • Subimperialismo brasileiro }\end{array}$ \\
\hline Pequeno silogismo 1 & Pequeno silogismo 2 & Pequeno silogismo 3 \\
\hline \multicolumn{2}{|c|}{ Homogeneização - Diferenciação - Hierarquização } \\
\hline
\end{tabular}

Fonte: Farias (2013a, p. 92).

se tornar real, é evidente que "[...] o princípio de uma boa problemática suprema transforma seguramente de imediato as categorias-figuras, a fortiori também as categorias setoriais, em categorias de um êxodo tentando alcançar uma melhor comunidade, um ser substancial" (BLOCH, 1981, p. 173-174), no quadro do movimento real que abole o estado de coisas presente (MARX; ENGELS, 1976). Tratase de um movimento de emancipação proletária que é internacionalista, e de modo algum imperial, cosmopolita, transnacionalista (ou nacionalista).

$\mathrm{Na}$ perspectiva da ontologia do devir, como antecipação concreta (BLOCH, 1981), além da modalidade lógica (problemática, hipotética, categórica, etc.), centrada na possibilidade real do modo e das formas de existência estatais capitalistas atuais, o processo dialético se subdivide, aliás, em dois grandes tipos, tal que convém agora de fazê-lo, pois se trata de apreender os elementos das formas estatais capitalistas atuais enquanto totalidade concreta, complexa e contraditória, ${ }^{1}$ a saber: a quantidade lógica se elabora no grande silogismo do modo estatal capitalista global em constituição, que existe realmente sob as formas nacionais, regionais e coletiva ideal planetária não rígidas, mas ao contrário abertas e dinamizadas pela qualidade lógica do desenvolvimento desigual ${ }^{2}$ inerente a todas as formas homogeneizadas, diferenciadas e hierarquizadas. 
Enfim, o silogismo das formas estatais capitalistas globais e suas figuras nacionais, transnacionais e coletiva ideal planetária são simplesmente, de fato, "[...] expressões no plano do pensamento de determinações do ser coexistentes[...]" (LUKÁCS, 2009, p. 79), ainda que contraditórias. Por sua vez, o imperialismo totaliza o capital e o Estado na escala global (ver quadro abaixo), de modo que "[...]o capital financeiro na sua perfeição significa o mais alto estádio de concentração do poder econômico e político nas mãos da oligarquia capitalista." (HILFERDING, 1979, p. 496). ${ }^{3}$

\section{SOCIEDADE E HISTÓRIA}

Uma totalidade envolvendo espaço, tempo e energia tomada diretamente da forma de existência natural não é um modelo adequado para uma abordagem crítica e revolucionária da forma de existência social, pela submissão desta última à parcialidade ideológica da reificação, que interessa particularmente à hegemonia burguesa na sua tentativa de abstrair a dinâmica própria à luta das classes como fator histórico decisivo. Com efeito, a luta das classes

[...] intervém na produção do espaço, produção cujos agentes são as classes, frações e grupos de classes. A luta das classes, hoje mais do que nunca, se lê no espaço. Na verdade, somente ela impede o espaço abstrato de se estender ao planeta, apagando literalmente as diferenças; somente ela tem uma capacidade diferencial, aquela de produzir diferenças que não sejam internas ao crescimento econômico considerado como estratégia, "lógica" e "sistema" (diferenças induzidas ou toleradas). As formas dessa luta são muito mais variadas do que antes. Fazem parte dela, é claro, as ações políticas das minorias. (LEFEBVRE, 2000b, p. 68).

$\mathrm{Na}$ abordagem espacial da própria experiência mundial, de acordo com sua hipótese estratégica, há $\mathrm{o}$ pressuposto - em termos de princípio e objetivo - de totalização concreta dos "[...]aspectos dissociados, a unidade dos movimentos e dos elementos separados." (LEFEBVRE, 2000, p. 77). Essa hipótese, portanto,

\footnotetext{
"[...] se pronuncia contra a homogeneização pelo Estado, pelo poder político, pelo mercado mundial e pelo mundo da mercadoria, homogeneização que se traduz praticamente por intermédio e no seio do espaço abstrato[...], [de um lado; e, do outro, mostra] [...]que as diferenças produzidas no curso dessas lutas teóricas e práticas diferem elas mesmas
}

das particularidades naturais e das distinções induzidas no seio do espaço abstrato existente..." (LIFEBVRE, 2000b, p. 77).

Porém, quando a razão dialética descarta a natureza, "reduzindo-a a uma abstração, negando-a, a filosofia da consciência corre o risco de deixar escapar uma parte essencial do conteúdo e da historicidade." (LEFEBVRE, 2000a, p. 141).

Um ser social isolado de sua essência contraditória não passa de uma simples descrição superficial, como também um ser social esvaziado de sua determinação histórica não passa de um instrumento da reificação burguesa (LUKÁCS, 1976).

Ao longo dos anos 1920, este intelectual orgânico do proletariado tornou-se um ferrenho crítico tanto da transposição ortodoxa (kautskismo) ou dogmática (stalinismo) da dialética da natureza para a dialética da sociedade e da história, quanto do determinismo e do positivismo próprio àquela transposição, que faz da subjetividade, nesta última dialética, um epifenômeno das correntes causais objetivas (LUKÁCS, 2001).

Conforme a reificação da geopolítica dominante, o Estado contemporâneo busca eternizar o espaço social capitalista na escala global,

[...] esmagando o tempo, reduzindo as diferenças às repetições, às circularidades (batizadas «equilíbrio», "feedback», «regulações», etc.) [...] Pondo-se e impondo-se como centro estável, definitivamente, das sociedades e dos espaços (nacionais)." (LEFEBVRE, 2000b, p. 31).

Assim, o Estado seria adequado à realização do prognóstico de Schumpeter (1984, p. 152-153), formulado em 1919, sobre "[...] o imperialismo, esta verdade de que os mortos reinam sempre sobre os vivos[...]", a saber:

[...] os elementos pré-capitalistas inseridos na nossa vida social podem muito bem manifestar uma forte aptidão para a sobrevida, e as potencialidades belicosas que contêm podem muito bem ser reanimadas em muitas circunstâncias, a evolução do mundo moderno tende no longo prazo a aniquilá-las.

O Estado como fenômeno histórico, porém, deve ser estudado nas suas características próprias, situado no seu contexto real, como consequência de suas relações formais e funcionais que se manifestam em modalidades sociais que de maneira alguma se podem confundir ou paralelizar, nem com as experiências espaço-temporais anteriores, nem com os fenômenos da natureza orgânica e inorgânica. $\mathrm{Na}$ longa duração, as abordagens burguesas tanto do ser 
social, quanto dos outros seres da natureza orgânica e inorgânica, já elaboraram suas metodologias científicas respectivas; mas, suas vias paralelas de analogia caricatural e suas transposições recíprocas permanecem presentes desde a Revolução Inglesa, passando pela série de Revoluções Industriais e, na contemporaneidade, pelo capitalismo organizado e submetido ao planejamento indicativo, até o advento nos tempos atuais da nova economia do capitalismo patrimonial e cognitivo. Em compensação, uma

[...] ontologia do ser social só seria concebível levando em consideração, por um lado, a especificidade das outras formas do ser, a interdependência e as diferenças relativamente a elas; e, por outro lado, o fato de que interdependência e oposição entre o ser das categorias, em sua objetividade verdadeira, em seu ser independente, e os procedimentos ideais através dos quais a consciência se esforça para apreendê-los, devem ser mantidos caso se queira realmente compreender os dois complexos. (LUKÁCS, 2009, p. 350).

O resultado do ecletismo ontológico dominante é uma bizarra articulação

[...] entre uma plena liberdade metodológica em questões particulares, objetos imediatos da pesquisa, e uma sujeição muito rígida a sua eficiência considerada do ponto de vista do mercado." (LUKACS, 2009, p. 146).

De um lado; e, do outro, muitas abordagens tiram "[...] da imagem do mundo elaborada pelo estado atual da ciência conclusões errôneas [...]", como aquela segundo a qual o homem deve "[...] ser concebido como um «átomo» da sociedade e do Estado." (LUKACS, 2009, p. 143), do mesmo modo que aquelas.

[...] que visam rejeitar a limine toda reforma, mesmo parcial, e por pouco revolucionária que seja, como contrária à natureza do ser social - sua natureza " orgânica » - e à natureza das coisas." (LUKACS, 2009, p. 155).

Os seres sociais, do mesmo modo que os seres orgânicos e inorgânicos, só podem se conceber inseridos no contexto cósmico. Em compensação, um pensador estruturalista afirma que "[...] a humanidade como totalidade natural não existe." (BADIOU, 2011, p. 50). Porém, seria enganoso querer ultrapassar os diversos quiproquós metodológicos por intermédio da clivagem absoluta entre os domínios do ser, considerando que

[...] somente a cooperação correta entre a experiência prática cotidiana e a conquista científica da realidade pode produzir uma abordagem autêntica da verdadeira natureza do ser, mas que essas duas componentes podem também ser providas de funções que bloqueiam essa progressão, sem falar dos momentos puramente ideológicos que podem se tornar seja um estimulante, seja um freio para essa cooperação, segundo os interesses sociais de classe. (LUKÁCS, 2009, p. 44).

No tempo presente, a globalização do american way of life é apresentada por seus partidários como uma evidência, um fato inevitável e, portanto, aceitável sem discussão. Ao inverso dessa ideologia,

[...] o mundo pode de fato ser conhecido e, na mesma medida, ser transformado, contra a opinião apriorística de um pessimismo banal ou de um otimismo bem atual que crê poder se contentar de consumir no lugar de ser militante. (BLOCH, 1981, p. 57).

Nas relações entre o homem e a natureza, por sua vez, existe uma abstração totalitária que simplesmente revela cada vez mais o menosprezo da ecologia - uma relação abstrata com as forças naturais que corresponde a uma [...] relação também abstrata do homem com o homem, obedecendo ao devir-mercadoria dos homens e das coisas no seu conjunto." (BLOCH, 1981, p. 242). Nesse caso, a primazia atribuída ao mercado livre e eterno provocou a mais extrema das reificações, o devir-mercadoria do mundo. Esse fetichismo ilustra que a ideologia inglesa fez uma trajetória do empirismo ao positivismo lógico que traz a marca do dilema burguês persistente de saber "[...] como seguir as vias da ciência sem renunciar às ilusões burguesas." (CORNFORT, 2010, p. 36). Trata-se de uma tomada de posição ideológica que corresponde à condição específica dos intelectuais (orgânicos, no sentido gramsciano do termo) da classe dominante, colocando [...] a discussão dos problemas sociais e morais num plano onde as contradições e as forças motrizes reais ativas na sociedade permanecem dissimuladas atrás da fachada da consciência social, sendo eternamente impedidas de se manifestarem (CORNFORT, 2010, p. 40). Aliás, esse tipo de intelectual

"[...] introduz uma separação rígida e mecânica entre o sujeito e o objeto. A ciência, para eles, somente pode levar em conta aquilo que está livre de toda intervenção do sujeito, e se exaltam com acentos de suprema indignação científica quando se atribui um papel ativo e positivo ao elemento subjetivo na história. (LUKÁCS, 2001, p. 29). 
Depois do fim da guerra fria, a ideologia inglesa passou a se combinar com a ideologia do novo século americano (FARIAS, 2004). Ambas se consolidaram e, em seguida, se reafirmaram como pensamento único que se tornou global, cujos supostos consensos são implantados em todo o mundo de maneira autoritária. Mas, desde as catastróficas experiências do século passado, é bem conhecido que nos períodos de crise estrutural, quando os reformistas burgueses estão na busca da resolução do antagonismo capital versus trabalho, preocupados com as dificuldades no nível da acumulação e da reprodução do capital social total, assim como com a redução dos conflitos entre os capitais numerosos, eles admitem o compromisso histórico, a regulação estatal e contratual (FARIAS, 2000), ainda que restringida pela primazia da iniciativa dos empresários e, portanto, marcada pela integração e pela socialização próprias à economia de mercado liberal. Aliás, o planismo, o estatismo e o mercado se combinaram na economia mista (MATTICK, 1972a,b). Portanto,

"[...] as tendências principais,
socialmente importantes, das
tentativas do pensamento de controlar
intelectualmente o ser, em suas
dimensões, segundo o caso, mais
importantes devem permanecer
estreitamente vinculadas a esse sistema
de regulação da tomada de posição
ideológica." (LUKÁCS, 2009, p. 293).

Em compensação, na posição crítica e revolucionária, as totalizações envolvem unidade e luta, como na crítica da economia política, em que o proletariado é negação da negação. Assim, ao realizar a ditadura dos magnatas do capital, o capital financeiro,

[...] ao mesmo tempo, torna a ditadura dos mestres do capital de um país determinado cada vez mais incompatível com os interesses capitalistas de outro país e a dominação do capital no interior do país cada vez mais incompatível com os interesses das massas populares exploradas pelo capital financeiro, mas impulsionadas por ele à luta. No confronto violento desses interesses opostos, a ditadura dos magnatas do capital se transforma finalmente na ditadura do proletariado. (HILFERDING, 1979, p. 496).

É muito provável que os regulacionistas planejem na forma de indicação e previsão de um crescimento equilibrado, de um futuro sem risco, benfazejo e repetitivo - quando os "fins imediatos" deixarão de sofrer

[...] a atração das tendências de sua trajetória e de sua desembocadura numa questão final; esquecendo- se facilmente, se degeneram em seu contrário e só podem se tornar naturalmente uma ideologia reformista camuflando a ordem estabelecida. (BLOCH, 1981, p. 249-250).

Portanto, os regulacionistas jamais antecipam, concretamente, no domínio da superação das condições objetivas que fazem com que a luta de classes continue a existir. É nessa ruptura, entretanto, que se enraíza a necessidade da democracia da genericidade proletária ${ }^{4}$, enquanto elemento decisivo no processo de extinção da forma estatal burguesa (MARX, 1975; LÊNIN, 1975). Trata-se de uma tarefa inacabada do passado, que permanece, então, um assunto favorito dos marxistas, sobretudo depois da Comuna de Paris, no sentido de que o vínculo criativo com o passado

[...] concerne sempre à aurora que aponta neste passado, uma aurora sempre destinada a advir de novo, atualizável, e que é preciso arrancar do mundo do aniquilamento, recriar e conduzir para frente. $(\mathrm{BLOCH}, 1981, \mathrm{p}$. 89).

Para quem leva a sério a tarefa de atualização, urge manter

[...] sem trégua no espírito esse longínquo fim utópico, visar e se colocar intencionalmente para além dos fins imediatos, caso se queira também pegar na raiz desses fins no curto prazo. (BLOCH, 1981, p. 252).

$\mathrm{Na}$ longa duração, longe de ter sido realizada no socialismo do século $\mathrm{XX}$, dito real e planejado central e autoritariamente, essa "utopia concreta" ${ }^{5}$ própria a uma prospectiva comunista, só tinha surgido de maneira sistemática a partir do século XIX, com a filosofia política marxista; desde então, na ideologia da classe explorada, dominada e humilhada,

[...] o interesse e a parcialidade não são em si um mal, de maneira alguma; na realidade, é o positivismo e seu apriorismo objetivista que constituem uma parcialidade perversa.

Cujo elogio dos fatos brutos oculta que eles "[...] sempre não passam de momentos reificados de um processo." (BLOCH, 1981, p. 51). Contra essa mistificação, urge

[...] uma parcialidade consciente, tomando partido pela transformação e pela [...] edificação da história segundo fins humanos, em favor de toda tendência objetiva que vai nesse sentido. Trata-se ao mesmo tempo de critérios que não se conformam com a simples realidade dos 
fatos, que até se opõem, se for o caso, a esses fatos e que pensam em fazê-los desaparecer, desde que representem momentos reificados de um processo. Concordando nisso com a tendência objetiva, isto é, com o ser segundo a possibilidade objetiva-real e com esse Mais ainda não advindo, que, portanto, também ainda não teve sucesso, através do qual ele ultrapassa a inautenticidade da ordem existente. (BLOCH, 1981, p. 147-148).

Atualmente, a reconstrução dialética das categorias estatais nacionais e regionais, bem como a configuração da categoria coletiva ideal planetária ${ }^{6}$, enquanto processo de abstração derivado, como genericidade estatal global - que "[...] não é nada mais do que a constatação no pensamento de um estado de coisas existente [...]", cuja natureza é contraditória na sua própria essência - se desfaz na ideologia dominante em proveito da reificação, ou até mesmo da construção abstrata fetichisante, segundo a mecânica das leis do desenvolvimento econômico (LUKÁCS, 2009, p. 79 e 207), e das outras potências correlativas geopolíticas, militares, tecnológicas, comunicacionais, etc. Em última instância,

[...] o antagonismo entre defesa e condenação do estado de coisas existente, a tomada de posição favorável ou contra o estádio alcançado pela genericidade, produzem necessariamente antagonismos ideológicos que, dos dois lados, estão intimamente vinculados à interpretação daquilo que deve ser considerado como ser real. Nessa ocasião, as experiências imediatas, como os métodos científicos que se tornaram - mais ou menos racionais, podem provocar distorções, frequentemente muito profundas, na compreensão do ser. (LUKACS, 2009, p. 293-294).

Assim, a constatação empírica estruturalista de uma economia-mundo, na longa duração, vem a ser uma necessidade natural e positiva do advento de um "Estado-mundo" sempre em gestação. Atrás do historicismo, do cosmopolitismo, do economicismo e da realpolitik se esconde frequentemente a abordagem idealista como "[...] uma violência intelectual exercida sobre o ser para torna-lo uniforme, estático." (LUKÁCS, 2009, p. 158). Uma abordagem materialista e dialética saberia, em primeiro lugar, que existe uma inclinação perigosa, como no caso do historicismo que só reconhece regras e normas específicas, "[...] a fazer abstração da ação do sujeito e a tomar as leis do mundo social atual como definitivas e eternas." (GOLDMANN, 1980 , p. 23). Em segundo lugar, que "[...] a história está caracterizada pelo fato de que as leis constitutivas das sociedades humanas elas próprias mudam com o devir dessas sociedades." (LUKACS, 2009, p. 65).

Para a tendência economicista e dogmática, ao contrário, mesmo em se tratando de uma grande crise, ela não seria capaz de oferecer aos proletários a possibilidade objetiva de uma grande transformação social, de acordo com seus interesses específicos e supremos, para a realização histórica da antecipação de uma sociedade comunista,

[...] que só pode existir entre homens inteiramente livres, comunidade que supõe a supressão de todos os entraves sociais, jurídicos e econômicos, à liberdade individual, a supressão das classes sociais e da exploração. (LUKACS, 2009, p. 14).

Nessa grande transformação social e histórica o Estado deve se extinguir, em vez de se estender através de formas estatais cada vez mais globalizadas, como na prospectiva ultra imperialista. Seguindo os passos dos revisionistas do começo do século XX, "[...] em vez de se apoiar na evolução tal que ela se apresenta atualmente, se abstraem dela voluntariamente, para sonhar." (LÊNIN, prefácio, in BUKHARIN, 1969, p. 15). Em compensação, uma abordagem materialista e dialética é decisiva para esclarecer e ultrapassar o esquema do pior que representa a perpetuação do sistema estatal burguês, do imperialismo, das guerras e das crises do capitalismo global, como havia antecipado Henri Lefebvre (1980, p. 175), quando este autor percebeu o marxismo como Um pensamento que veio a ser mundo. Nessas circunstâncias, a Experiência mundo blochiana sublinhou uma regra:

[...] do mesmo modo que não se deve optar logo no sentido de um pessimismo que leve à resignação, mas somente de um pessimismo militante, também não será admitido um otimismo garantido, mas exatamente um otimismo militante - aquele do homem que transforma o mundo na fronte do processo histórico. (BLOCH, 1981, p. 142).

No quadro da crise global impõe-se aos marxistas críticos e revolucionários a tarefa de atualização da dialética entre vontade transformadora e razão crítica no contexto atual, colocando a problema da transição socialista, orientada pela antecipação concreta da superação das condições objetivas que fazem com que a luta de classes continue existindo. Nessa fronte, existe uma "[...] parcialidade assumida: parcialidade vermelha, mas, também, com a consciência marxista que acompanha a sua ciência, objetividade conformadora, projetando novas formas. (BLOCH, 1981, p. 51). 
Contra o slogan de Margareth Thatcher, There is no alternative, tanto o otimismo militante, quanto o pessimismo militante "[...] têm por divisa a fórmula eminentemente concreta e em nada resignada - not at all -: Tanto pior para os fatos [...]; pois,

[...] o real contém no seu ser a possibilidade de um ser semelhante à utopia; ele ainda não existe, mas seu prévio-aparecer existe, fundado e susceptível de sê-lo, assim como seu conceito, seu princípio utópico, na superestrutura (BLOCH, 1981, p. 229).

Além disso,

[...] a história pode, então, ao menos ensinar que a lei da classe dominante nem sempre é capaz de impor o jeito do encaramujo àquele que almejaria, através da revolução, andar com a cabeça erguida. O ímpeto revolucionário, o mais ultra que exprime seu prévioaparecer utópico, é imanente ao avanço da história. É verdade também que tudo que projeta para além dos fatos encerra um perigo, e que esse perigo não deve ser negligenciado; mas, nesse caso, é preciso recusar as calúnias e os malentendidos interessados que atribuem tanta importância à apresentação banal da utopia como um sonho impossível; é preciso também recusar uma concepção que, ao pretender ser muito prática, atribui aos fins imediatos uma importância reformista tão grande que termina declarando que os fins distantes Ihes parecem indiferentes e enganosos. (BLOCH, 1981, p. 180).

Fora da parcialidade autenticamente marxista, e, portanto, atualizada no pensamento e na práxis, não existe problemática atinente ao modo e às formas de existência estatais, assim como sua extinção na atualidade. Ao mesmo tempo, os conformistas mantêm-se fiéis à lógica burguesa seja empirista, seja positivista, no pior dos casos, por sua duvidosa "[...] insistência em se dizerem neutros diante dos valores [...]", mas que "[...] só estão liberados dos interesses na medida em que deixaram atrás deles o interesse de sua classe em tudo obscurecer." (BLOCH, 1981, p. 180). Precisamente na "lógica formal", os conceitos trazem a marca da

[...]ideologia passada e que ali aparecem elementos bem evidentes que não passam de reminiscências de uma falsa consciência passada, interiorizada e sobrevivendo sem ser controlada." (BLOCH, 1981, p. 48).

Entretanto, a lógica dialética incorpora a lógica formal como um de seus elementos. Por intermédio dela é possível mensurar tanto as quantidades nas relações sociais reificadas, quanto construir figuras atinentes à estrutura das formas sociais e históricas. Isso é especialmente importante para apreender as mudanças no seio do ser social no contexto do capitalismo global. Porém, é preciso criticar o tratamento "exato» de pseudoproblemas na perspectiva de uma especialização delimitada, que facilita e favorece a subordinação das ciências particulares sob a manipulação do capitalismo universal-porexemplo, a análise econômicaburguesa se constituiu como uma ciência particular, sob "[...] as exigências da " diferenciação em especialidades ", da limitação da " exatidão " consecutiva a esta diferenciação[...]" - e que "[...] tornaram as ciências particulares ainda mais incapazes de compreenderem em termos ontologicamente corretos mesmo os momentos parciais do processo global." (LUKÁCS, 2009, p. 314). Portanto, a superação dos fetichismos da mercadoria, do capital e do estado capitalista na escala mundial inclui a superação da ideologia angloamericana que se tornou global (GOWAN, 2003) por intermédio de uma abordagem da herança científica, do empirismo ao positivismo, bem distinta daquela das ideologias burguesas do mercado mundial seja regulado seja livre e eterno ${ }^{8}$. Porque o real que eles alegam

[...] é de fato tão separado dos valores que ele se contenta na maioria dos casos em conservar e fetichisar as realidades existentes, isto é, dominantes, que transforma em fatos indiscutíveis. (BLOCH, 1981, p. 51).

Assim, na utopia abstrata do mercado mundial livre e eterno,

[...] em nome da ciência, políticas foram aplicadas de maneira frequentemente cega em muitos países há trinta anos. $\mathrm{Na}$ visão neoliberal ainda dominante, que descreve um mundo feito de agentes econômicos individualistas e lúcidos em concorrência uns com os outros, a liberalização geral dos mercados deveria matematicamente conduzir ao crescimento máximo e ao optimum econômico. (ASKENAZY; COUTROT, 2010, p. 9) ${ }^{9}$

Ao mesmo tempo em que os mesmos fatos teimam em mostrar - a contracorrente da utopia abstrata - que é urgente apreender e mudar a situação concreta do modo e das formas de existência estatais capitalistas globais. Desde logo, importa ter a metodologia científica necessária à análise concreta marxista, que "[...] não é o contrário de uma utopia, mas, ao contrário, o novum de uma utopia concreta." (ASKENAZY, COUTROT, 2010, p. 180). Essa análise verá "[...] se desprender de si um futuro no passado ou, mais exatamente, um 
postulado futuro que é necessário concluir com sucesso. É o caso das revoluções que fracassaram [...]"; na medida em que mesmo "o passado é capaz de subsistir", desse modo,

[...] na tensão do tempo voltado ao futuro, o homem pode retornar a este passado através da lembrança ou da interpretação para reabilitá-lo em parte ou para melhorá-lo revolucionariamente. (ASKENAZY, COUTROT, 2010, p. 99).

Enfim, compreendida na forma de um

instante que se rebate realmente na questão final, toda prática radical, tomando as coisas pela raiz, é incontestavelmente um ainda-não, a utopia derradeira ainda inteiramente em suspenso. (ASKENAZY, COUTROT, 2010, p. 247).

Foi relevante, então, começar pela conexão entre atualização da ontologia do ser social e atualização das formas estatais.

\section{VIRTUAL E REAL}

A perspectiva revolucionária das formas historicamente determinadas deverá combinar-se à crítica das formas sociais presentes para determinarIhes os limites relativos e a possível superação. Não há superação real do mundo capitalista existente, por intermédio de um momento socialista, "[...] liberando a sociedade por inteiro de todas as condições da existência que trazem sobre elas a marca do trabalho alienado[...]", sem consolidar uma "[...] aliança com o mundo ainda não existente, com as propriedades do real que são portadoras de futuro." (BLOCH, 1977, p. 492). Portanto, a antecipação concreta é uma categoria marxista muito útil para sair da armadilha de uma ontologia do ser social contemplativa, fechada, estática ou terminada para sempre, que associa até mesmo o pensamento crítico com as antigas formas sociais e históricas que ele pretende ultrapassar (VINCENT, 1987. Assim, as experiências positivistas da forma Estado nacional social remetem ao abandono institucionalista político-sindical da ruptura operária, em proveito de sua integração no compromisso histórico socialdemocrata (MATTICK, 1972a; 1972b) - na realpolitik do socialismo como ideologia do bem-estar e do consenso Capital-Trabalho. Na experiência do socialismo real também se buscou integrar o proletariado num projeto burocráticoestatista, no qual as organizações classistas se diluem no aparelho estatal. Por sua vez, o socialliberalismo brasileiro integrou ao seu governo parte substancial das lideranças das organizações ditas não governamentais, sindicais e políticas. Em compensação, o socialismo como ideologia da classe revolucionária dos proletários explicita clara e obviamente a primazia de seu interesse específico, que, por isso mesmo, é coerente com

[...] a escolha confessa, passível de formulação, radicalmente engajada e comprometida, graças à qual a utopia torna-se finalmente, na ideologia revolucionária do futuro, uma utopia concreta. (BLOCH, 1981, p. 51).

Trata-se do "[...] sonho de uma Coisa que reside na imaginação objetiva-real[...]", no seio "[...] da qual o objeto e o sujeito se reencontram, se entrelaçam em plena reciprocidade[...]", não num sonho impossível, porque

[...] lá é o topos objetivo das possibilidades objetivas-reais - mas esse topos permanece ele próprio aberto, orientado para o Novum que reside nas inesgotáveis ilustrações de algo ainda desconhecido e constitui, penetrado que é do conteúdo de um fim utópico, o sonho diurno - dir-se-ia até mesmo o sonho de luz - presente no seio do próprio mundo a título de utopia concreta. (BLOCH, 1981, p. 246).

Assim, diante do mecanismo do duplo molinete que assegura a reprodução dos elementos do capital produtivo individual, é sob o horizonte da utopia concreta da extinção da forma-Estado nacional capitalista-e, portanto, de suas intromissões no nível das condições prévias mercantis desenvolvidas, assim como de sua mediação da contradição entre os indivíduos que personificam o capital e a força de trabalho - que advém a possibilidade do novo, no começo do século XXI, nas relações especificamente dialéticas:

[...] o trabalhador, cuja qualidade indelével, até então, era de ser vinculado ao capital e de desaparecer nele contribuindo na função que é a sua: produzir mais-valia, este trabalhador, através da revolução, se eleva acima do conjunto instrumental que o explorava, abafa os tambores dominantes e cria sua própria música, transformando a sociedade de classe em sociedade sem classes e ele próprio se tornando conserto. (BLOCH, 1981, p 44).

A atualização da utopia concreta da emancipação da classe explorada, dominada e humilhada no começo do século $X X I$ não remete a um desaparecimento ideológico pós-moderno do ser social e histórico provocado pela submissão de todo sujeito coletivo à conjuntura planetária autoritária da era da mundialização, mas à reafirmação da possibilidade de extinção das formas estatais capitalistas que se tornaram globais. Também, "[...]essa antecipação, presença de uma parcela 
de utopia na ideologia, quer se trate de um eco revolucionário do Cidadão [...]" do mundo, quer "[...] se trate de uma visão transcendente de nosso rosto [...]" para além do tempo presente e da ideologia dominante,

[...] é o fermento do excedente; essas reaparições são aquilo que o torna possível e the atribui, fora da ideologia, um fundamento sempre mais amplo, sempre mais aberto. (BLOCH, 1981, p. 49).

$\mathrm{Na}$ crítica da filosofia política das formas estatais capitalistas globais, é combatida uma ideologia dominante,

[...] uma ideologia superada, uma ideologia cujo sentido é passível de ser finalmente penetrado e que se revela como a retomada, a justificação de relações sociais, até mesmo de um mundo, acabados, imutáveis, encerrados sobre eles próprios, fechados a todo futuro; sob esse ângulo, nenhum excedente que ultrapassasse 0 espírito dos mestres se revelaria nela como uma herança. (BLOCH, 1981, p. 26).

Portanto, a atualização da utopia concreta da democracia da genericidade proletária resulta, também, "[...] de um imaginário social que tira sua força da crítica que faz da estreiteza e da unidimensionalidade do real cristalizado [...]" (VINCENT, 1987, p. 42). Então, não há lugar para a utopia abstrata, porque, "[...] na previsão segundo a qual a transformação socialista das sociedades capitalistas, com a passagem real do socialismo autenticamente realizado ao comunismo [...]", é a "[...] aspiração humana à genericidade autêntica [...]" que é chamada "[...] a assumir um papel decisivo na modelagem do fator subjetivo." (LUKÁCS, 2009, p. 279). Esse fator é próprio à consciência de classe política,

[...] se orientando para uma lógica da análise das situações e das tendências, cuja realização prática assegura imediatamente $\mathrm{o}$ triunfo da classe operária e, em seguida, sua superação futura." (BLOCH, 1981, p. 240).

Em suma,

[...] essa elaboração real depende das possibilidades tendenciais que são as suas na realidade estabelecida, ela é dependente de possibilidades objetivasreais que, por sua vez, devem ser assimiladas pelo conceito a fim de que aquilo que está presente em germe nelas torne-se realizável. Em seguida, a concepção das possibilidades objetivas- reais que permitem progredir [...] não é mais suficiente: essa possibilidades somente são realizáveis se 0 fator subjetivo se implica com todas as suas forças - intervindo aqui, no processo histórico, em função de uma ordem de destino social e econômica que o leva a promover aquilo cujo momento já chegou no nível objetivo e real, o possível concreto. Sozinhos, por mais necessários que eles sejam, os fatores objetivos da potencialidade real não trazem nenhuma garantia de sucesso; são dependentes do poder de tornar diverso, da potência do sujeito realizador. Realizar significa, então, a implementação de um poder subjetivo para realizar um possível objetivo real, até mesmo também revelar novas possibilidades; realizar designa a intervenção, a irrupção do fator subjetivo na ordem ainda indecisa, em suspensão, das condições já existentes a fim de que estas liberem a sua potencialidade sob a forma do fator objetivo na atualidade da efetuação. (BLOCH, 1981, p. 245-246).

Por outro lado, o socialismo na perspectiva comunista é "[...] a ideologia da classe revolucionária dos trabalhadores, denunciando e rejeitando justamente as ideologias da dominação que tinham reinado até então." (BLOCH, 1981, p. 49). Nessa perspectiva, a crítica da ideologia kautskista do ultra imperialismo assumiu um papel determinante. O novo imperialismo liberal do começo do século $\mathrm{XXI}$ é tão resistível quanto aquele do começo do século $X X$, pois a articulação criativa com o passado permanece atinente

[...] à aurora que aponta no passado, uma aurora sempre destinada a advir, de novo, atualizável, e que é preciso arrancar do mundo do aniquilamento, recriar, levar para frente. (BLOCH, 1981, p. 89).

Hoje, permanece decisivo fazer a crítica da antiga ideologia kautskista, sob sua nova roupagem pós-moderna e neoliberal, pois

"[...] é verdade que a ideologia passada pode também se manter sob uma forma nefasta, quando um tipo de dominação passada se detém, para simples fins de restauração, e sem a mínima revivescência produtiva, em ocultações travestidas e enfeitadas, emprestadas ao passado." (BLOCH, 1981, p. 49).

Em compensação, a ideologia portadora de excedente - relativamente ao imperialismo renovado (ou do século XXI) pelo cosmopolitismo democrático ou europeu, etc. - "[...] tem uma função bem diversa 
e pode até mesmo se aliar ao olhar destrutivo, incorruptível, a esse olhar de detetive através do qual o marxismo destrói os mitos." (BLOCH, 1981, p. 49). Um desses mitos é o advento do socialismo como tendência mecânica por meio das latências do ultra imperialismo, ou, mais modestamente atualizada, é a tendência ao progresso social planetário através das latências liberal e globalizantes do imperialismo, mas com a repetição das regulações estatais e contratuais exigidas em toda conjuntura de crise global, ${ }^{10}$ quando "[...] na história, a utilização de todo negativo como locomotiva do progresso não é sempre possível nem certamente necessário." (BLOCH, 1981, p. 140-141). Então,

[...] sabe-se que a totalidade, em marcha na tendência, porém entravada e ainda não alcançada, inclui ao mesmo tempo o elemento utópico fundador da tendência: a latência... A latência é a estrutura na qual se exprime, em favor da tendência, a estranha preexistência de sua orientação e de sua antecipação; em outros termos, a latência é o modo segundo o qual o conteúdo de um fim, que ainda não é, se faz valer numa tendência. Por causa de seu caráter de Novum o latente autêntico não está jamais vinculado à repetição mecânica [...] (BLOCH, 1981, p. 141-142).

Contra o idealismo e o positivismo no seu comprometimento com a perpetuação do capitalismo é preciso opor tanto a humanização da natureza, quanto a naturalização do homem, no seu sentido imanente, em suas interconexões, de acordo com o materialismo dialético e histórico. Em suma,

[...]a materia universalis é aquilo que assegura a coesão íntima e extrema do mundo, de um mundo sempre inacabado nas suas origens assim como nos seus fins. Portanto, a matéria tem também sua utopia; na possibilidade objetiva real, esta deixa de ser uma utopia abstrata. (BLOCH, 1981, p. 61).

Obviamente, falta mostrar em seguida que há necessidade de apreender essas interconexões concretas, como um dos pressupostos da transformação do mundo.

\section{CONCLUSÃO: práxis e transformação}

Enquanto persistir a luta de classes na escala global, a parcialidade marxista deve manter a sua intervenção internacional sob a forma tanto [...] de um engajamento moral pela causa dos oprimidos [...]", quanto

"[...] de uma tomada de partido que encontra de fato seu fundamento na objetividade real - porque só toma partido por conhecer e revelar para fins teóricos e práticos as tendências desse real objetivo. (BLOCH, 1981, p. 50-51).

$\mathrm{Na}$ perspectiva marxista, portanto, não basta ter "[...]um pensamento categorial exato[...]" concernente à formação socioeconômica capitalista, sem nenhum vínculo com ações transformadoras, embora seja verdade que ele tem

[...] a primeira palavra, a que intervém primeiramente no tempo e que, em todo ângulo, abre um espaço, mas a função que assume faz com que não tenha a última palavra, que é a da ação, da transformação [...]" (BLOCH, 1981, p. 230).

A abordagem marxista das formas estatais capitalistas globais do futuro se articula com a utopia concreta de sua extinção,

[...] com o conhecimento penetrante de tudo o que existe de ruim na ordem estabelecida, com qualidades do real portadoras de futuro, com a concepção de tendências e de latências que encerram não somente possibilidades negativas, mas, também, positivas." (BLOCH, 1981, p. 51).

Uma grande transformação social e histórica - sendo norteada pela antecipação marxista de um mundo melhor e conforme a negação da negação envolve a superação efetiva da natureza mercantilindividualista e da exploração do homem pelo homem. Entretanto, longe da práxis da ordem e do progresso,

[...] o excedente só pode desembocar sobre uma herança caso se encontre ele próprio conduzido e revolucionado por um novum, por alguma coisa cuja originalidade ainda não foi esgotada pela história. (BLOCH, 1981, p. 52).

É perfeitamente possível apreender a totalização das formas estatais capitalistas globais sem cair no fetichismo que só destaca o seu objetivismo, sob uma suposta autonomia relativamente aos interesses - essa globalização torna-se, então, o mais robusto dos subjetivismos burgueses contemporâneos. Em contrapartida, esse todo, como o possível concebido, grande silogismo de maneira preeminente,

[...] daquilo que está aberto a uma transformação através de um fazer, contribui a título de tendência à nossa intervenção, concede-lhe sua bênção perfeitamente secular. Essa intervenção é o poder de tornar diverso, a potência (potentia), isto é, o fator subjetivo; a 
afluência que ela encontra no real, a possibilidade objetiva-real do que pode ser tornado diverso, é a potencialidade, o fator objetivo. (BLOCH, 1981, p. 133134).

$\mathrm{Na}$ realidade, é preciso conquistar por meio da práxis consciente um ponto de vista liberado das ilusões subjetivistas e objetivistas, bem como chegar a uma reflexão bem especialmente intensa da parcialidade comportada pelo interesse na emancipação dos indivíduos globalmente explorados, dominados e humilhados - que terminam sempre atualizando esse não-concluso; que, por sua vez, é também de natureza categorial, e que

[...] resulta da transformação radical daquilo que visa e, como elemento de uma teoria do conhecimento, escapa tanto do subjetivismo, quanto do seu contrário aparente, o objetivismo neutro[...] (BLOCH, 1981, p 52).

$\mathrm{Na}$ sequência, as categorias da elaboração das formas estatais capitalistas globais obedecem à "[...]tendência objetiva da história[...]", que "[...]é, do começo ao fim, engajada: engajada na experiência da história, na formação de seu na direção-deque, sua finalidade, e seu sentido, seu para-que." (BLOCH, 1981, p. 52). Enfim, "[...]a mais importante das determinações parciais[...]" é aquela atinente à

[...] possibilidade objetiva-real que constitui o ser-diante-de-nós, o serainda-aberto do mundo em devir. Nele, a liberdade é sempre a possibilidade de outro advir, de um fazer-outro, e se não existisse essa descontinuidade fecunda que ela implica, só conheceríamos a submissão a leis imutáveis e tirânicas ao infinito. (BLOCH, 1981, p. 133).

As constatações, as confirmações e até mesmo as provas trazidas a posteriori são duvidosas, se

[...] a teoria está desfigurada pela ideologia e que a prática, especialmente, não recebe da teoria que deve orientála[...] uma referência concreta dos homens à natureza e aos outros homens. (BLOCH, 1981, p. 241).

No marxismo, essa referência radical foi elaborada de maneira ampla e profunda, porque $o$ método da verdadeira teoria-prática estabelece os fins da ação a partir de "[...] uma análise do mundo que o envolve e que precisa mudar; para essa prática, o socialismo é a condição sine qua non de sua relação com o fim último." (BLOCH, 1981, p. 241), isto é, a superação tanto da exploração, da dominação e da humilhação do homem pelo homem, quanto do processo de "[...] destruição radical de suas condições de existência naturais por menosprezo da ecologia." (BLOCH, 1981, p. 242). Trata-se de impulsionar essa "[...] imanência ao extremo na proximidade máxima da Causa do homem e da Coisa do mundo. (BLOCH, 1981, p. 254). Enfim, "[...] a realização do próprio realizador [...]" enquanto sujeito coletivo que busca atingir conscientemente esse fim último

[...] não se produzirá no curto prazo mesmo se ela é preparada por todas as supressões, ao mesmo tempo antecipadoras e práticas, das causas da miséria e da opressão, do menosprezo e do aviltamento. (BLOCH, 1981, p. 247).

Em suma, a realização do próprio realizador implica "[...] a relação teoria-prática sob sua forma mais central." (BLOCH, 1981, p. 245). Isso significa que

[...] se a posição é esclarecida pela determinação lógica - e, sem essa última, a ação que coloca se realizaria cegamente -, essa prática teórica própria à determinação lógica deve passar pela prova da prática, sem o que a determinação esclarecedora seria não somente contemplativa como também representaria uma deserção diante da transformação real e se esvaziaria de toda realidade. (BLOCH, 1981, p. 245).

As categorias da elaboração serão relacionadas (em outra ocasião) com as formas estatais realmente existentes no contexto situado para além do fordismo e na era da globalização, partindo do princípio seguinte:

[...] enquanto adaptação ativa do homem ao seu ambiente, o ser social repousa, em primeiro lugar e irrevogavelmente, sobre a práxis. Todas as características reais importantes desse ser só podem ser compreendidas a partir do exame ontológico dos pressupostos, da essência, das consequências dessa práxis no seu ser específico. (LUKÁCS, 2009, p. 73).

Esse autor sublinha, entretanto, a necessidade de recusar as abstrações idealistas - sob a primazia do momento lógico, ou mesmo do logicismo - que se traduzem "[...] pela tentativa contínua de fazer das categorias lógicas transmitidas pela história da filosofia e pela práxis o fundamento intelectual da nova visão do mundo." (LUKÁCS, 2009, p. 158). Assim, o modo e as formas de existência estatais capitalistas globais, como categorias de uma formaEstado desprovida de determinações não é uma forma-Estado,

[...] o que não exclui, é claro, que o pensamento, nas operações lógicas, 
possa fazer abstração das determinações do ser e colocar o conceito de um ser desprovido de determinações." (LUKÁCS, 2009, p. 167)

É somente no momento da "própria realização" do ser social, quando o objetivo é sua implementação,

[...] que o pensamento se torna verdadeiramente rigoroso e fluido ao mesmo tempo, que ele tira as lições da ação para fixar novos fins, que ele retém dela perspectivas novas para guiar novas ações. (BLOCH, 1981, p. 240).

Então, é necessário passar ao ato da intervenção que concebe especificamente marxista, "[...] essa situação de relacionamento prático próprio ao ato de conceber relativamente ao seu correlato objetivo real, a predicação categorial em ação no mundo [...]"; trata-se, aqui, do modo e das formas de existência estatais capitalistas globais, cujas relações e conjuntos coerentes "[...] que se encontram no mundo real são tanto reais quanto conformes à razão e existe aí, também, um correlato lógico contraditório, sem capitulação em nome do fetichismo dos fatos [...]"; portanto, o mundo apresenta, em cada um de seus domínios estatais, um meio mediador acessível ao pensamento; apesar do fato que

[...] esse meio não é, rigorosamente falando, pensamento, razão, mas somente da mesma ordem que a razão, suas categorias [...] podem ser definidas como aquelas de um correlato, de uma inclinação da lógica no próprio seio do contexto processual do mundo: no quadro da dialética real. (BLOCH, 1981, p. 76).

A passagem pelas categorias da elaboração é um momento incontornável, posto que o ser social e histórico implantado na escala global só pode ser considerado ontologicamente como um todo concreto ao ser apreendido em toda a riqueza de suas determinações, das mais simples às mais complexas. In fine,

[...] para o controle intelectual e, sobretudo, para o controle prático de um determinado existente, em circunstâncias dadas e em casos concretos, pode ser útil, e, às vezes, até mesmo inevitável, fazer abstração de certas determinações do ser. Entretanto, é preciso jamais esquecer que na ocasião de tais operações de abstrações, essas, por elas mesmas, não podem em nenhum caso provocar a mínima transformação no ser que visam. (LUKÁCS, 2009, p. 181).
Portanto, as categorias da elaboração já devem estar liberadas dessas distorções ideológicas em proveito de um pensamento que, ao mesmo tempo,

[...] objetiva e extrai o imediatismo a fim de refletir, mas, também, de abrir para novas formas a imagem daquilo que se manifesta objetivamente, sob a forma de objeto, no conhecimento e na sua prática. (BLOCH, 1981, p. 26).

Assim, na evolução histórica,

[...] as categorias podem realizar os seus processos individuais, determinados pelos processos de conjunto, somente na simultaneidade da continuidade e da mudança. $O$ fato de que só possam ser tornadas conscientes no pensamento do sujeito constitui um momento ontológico muito importante e irrevocável do ser social, mas isso não muda nada quanto ao caráter objetivo, existente em si, do processo geral e das categorias, nas quais as mudanças históricas das formas de objetividades permitem cada vez ao ser no interior desse processo. (LUKÁCS, 2009, p. 413).

As categorias atinentes ao modo estatal capitalista global e suas formas de existência estatais capitalistas nacionais, transnacionais e coletiva ideal planetária se inserem, então, num processo social total e irreversível constituído pela própria história. No contexto da globalização inserem-se dois elementos, a saber:

[...] o Estado e seu espaço. As diferenças jamais disseram a sua última palavra. Vencidas, elas sobrevivem. Batem-se às vezes ferozmente para se afirmar e se transformas através da provação... A classe operária, por sua vez, também não disse sua última palavra; segue sua trajetória, ora subterrânea, ora a céu aberto. Não se desembaraça facilmente da luta de classes que assumiu formas múltiplas [...] (LEFEBVRE, 2000b, p. 32).

Nas visões atualizadas do Estado, tendo por essência a divisão capitalista do trabalho que serve de eixo para a luta de classes, "[...]diferentes do esquema empobrecido que traz este nome e que não se encontra em Marx, ainda que seus portadores se reclamem dele. (LEFEBVRE, 2000b, p. 32), a natureza da construção estatal planetária é rica em determinações que envolvem, no seio da ontologia fundada no trabalho, a dialética do universal e do específico, a distinção do governo e do Estado propriamente dito, a gênese territorial e o processo de particularização e autonomização relativa, o fetichismo como reificação e como personificação, a subsistência em potência e em ato, a teleologia sistêmica e antissistêmica (FARIAS, 2013a). 


\section{REFERÊNCIAS}

AGLIETTA, Michel; BERREBI, Laurent. Désordres dans le capitalisme mondial. Paris: Odile Jacob, 2007.

AMIN, Samir. Au-delà du capitalisme sénile. Paris: PUF, 2001.

ASKENAZY, Philippe / COUTROT, Thomas et alii. Manifeste d'économistes atterrés, MayenneFrance: Les Liens qui Libèrent, 2010.

BADIOU, Alain. La relation énigmatique entre philosophie et politique. Paris: Germina, 2011.

BENSAIID, Daniel. Éloge de la politique profane. Paris: Albin Michel, 2008.

BLOCH, Ernst. Experimentum Mundi. Paris: Payot, 1981.

Sujet-Objet: Éclaircissements sur Hegel, Paris: Gallimard, 1977.

BOUKHARIN, Nicolas. 0 imperialismo e a economia mundial. Rio de Janeiro: Laemmert, 1969.

BRZEZINSKI, Zbigniew. "The global political awakening". The New York Times, New York, 2008. Disponível em: http://www.nytimes.com/2008/12/16/ opinion/16iht-YEbrzezinski.1.18730411.html?_r=1. Acesso em: 06 fev. 2011.

CHESNAIS, François. « La dette publique, question névralgique de la lutte des classes en Europe » : Carré Rouge, $n^{\circ} 44,2010$, p. 98. Disponível em: http:// www.carre-rouge.org/IMG/pdf/G-_Chesnais_1_.pdf. Acesso em: 06 fev. 2011.

COLLECTIF D'ATTAC. Une autre ONU pour un autre monde. Bruxelles: Tribord, 2010.

CORNFORTH, Maurice. L'idéologie anglaise. Paris: Delga, 2010.

DUMÉNIL; CASSEN (org.). L'Empire de la guerre permanente. Paris : Mil et une nuits, 2004.

ENGELS, Friedrich. Anti-Dühring. Paris: Sociales, 1977.

FARIAS, Flávio Bezerra de. O Estado capitalista contemporâneo. São Paulo: Cortez, 2000.

A globalização e o Estado cosmopolita. São Paulo: Cortez, 2001.

Filosofia política da América. São Paulo: Cortez, 2004.
$2013 a$

O modo estatal global. São Paulo: Xamã, $2013 b$

O imperialismo global. São Paulo: Cortez,

GOLDMANN, Lucien. Recherches dialectiques. Paris: Gallimard, 1980

GOWAN, Peter. A Roleta Global. Rio de Janeiro: Record, 2003.

HARDT, Michael ; NEGRI, Antonio. Empire. Paris : Exils, 2000.

HILFERDING, Rudolf. Le capital financier. Paris : Minuit, 1979.

KORSCH, Karl. Karl Marx. Paris: Champ Libre, 1971.

1976.

Marxisme et philosophie. Paris: Minuit,

Teoría marxista y acción política. México: Siglo XXI, 1979.

KOSIK, Karel. La dialectique du concret. Paris: Maspero, 1978.

LEFEBVRE, Henri. Une pensée devenue monde. Paris: Fayard, 1980.

Métaphilosophie. Paris: Syllepse, 2000a.

$\overline{2000 b}$

La production de l'espace. Paris: Anthropos,

LÊNIN, V. I.Oeuvres choisies. 3 Tomos. Paris; Sociales; Moscou; Progrès, 1975.

LUKÁCS, Georges. Prolégomènes à l'ontologie de l'être social. Paris: Delga, 2009.

Dialectique et spontanéité. Paris: Les Éditions de la Passion, 2001.

Histoire et conscience de classe. Paris: Minuit, 1976.

LUXEMBURGO, Rosa. Organizational questions of the Russian Social Democracy. [S. I.: s. n.], 1904. Disponível em:<http://www.marxists.org/ archive/luxemburg/1904/questions-rds/index.htm>. Acesso em: 1 jan. 2013.

MANDEL, Ernest. La réponse socialiste au défi américain. Paris: Maspero, 1969.

MARX, Karl. Le Capital. Paris: Sociales, 1976. 
Contribution à la critique de l'économie politique. Paris: Sociales, 1977.

Manuscrits de 1844. Paris: Flammarion, 1996.

Critique du Programme de Gotha. Pequim: Langues Étrangères, 1975.

ENGELS, Friedrich. L'idéologie allemande. Paris: Sociales, 1976.

MATTICK, Paul. Intégration capitaliste et rupture ouvrière. Paris: EDI, 1972a.

Marx et Keynes. Paris : Gallimard, 1972b.

NYE JR., Joseph S. L'Amérique est-elle un empire? Project Syndicate, Praga, 2004. Disponível em: http://www.project-syndica-te.org/commentary/nye5/ French. 26/01/2004. Acesso em: 25 fev. 2011.

SARTRE, Jean-Paul. Questions de méthode. Paris: Gallimard, 2005.

SCHUMPETER, Joseph. Impérialisme et classes sociales. Paris: Flammarion, 1984.

VINCENT, Jean-Marie. Critique du travail. Paris: PUF, 1987.

\section{NOTAS}

$1 \quad$ Ver Karel Kosik (1978).

2 Ver Lefebvre (1980, p. 135) e Mandel (1969, p. 9).

3 Um estrategista usou a cortina de fumaça de um silogismo logicista e vulgar para ofertar no mercado a "[...] era das comunicações mundiais", onde "o poder estratégico não é mais tão concentrado, mas, ao inverso, distribuído entre as nações num esquema que se parece com um jogo de xadrez complexo tridimensional [...]", a saber: $1^{\circ}$ o poder militar unipolar estadunidense; $2^{\circ}$ poder econômico combinado entre EUA e UE; $3^{\circ}$ distribuição caótica do poder nas relações internacionais, (NYE JR., 2004, p. 1).

4 "[...] A relação real ativa do homem consigo mesmo como ser genérico, isto é, a afirmação de seu ser como ser genérico real, como ser humano, se tornará possível só se, por um lado, o homem realiza efetivamente a totalidade de suas forças genéricas - 0 que pressupõe a ação comum dos homens enquanto resultado da história - e se, por outro lado, essas forças se apresentam diante dele como objetos, o que por seu turno só é possível sobre a base da alienação." (MARX, 1996, p. 165).

5 Em 1973, Burghart Schmidt tomou uma posição “[...] contra a confusão comumente difundida entre a utopia concreta e o planejamento [...]", pois, na realidade, " o plano se refere a uma previsão, enquanto que a utopia concerne uma antecipação. No prognóstico implicado pelo plano a gente se preocupa em tirar conclusões para o futuro partindo de fenômenos regulares que, aliás, só oferecem garantia apenas em virtude de sua conformidade a leis ou, pelo menos, de sua repetição constante. Em compensação, na antecipação que implica a utopia, a gente se preocupa em controlar a repetição para transformá-la e romper com sua lei." (BLOCH, 1981, p. 122).

6 Aplicação do conceito de Estado enquanto capitalista coletivo ideal (ENGELS, 1977).

7 Cf. Jacques Bidet sobre "O mundo de hoje visto na sua tendência histórica”. (COLLECTIF D'ATTAC, 2010, p. 30-33).

8 Sobre suas utilizações de números, modelos e cálculos, embora seja "[...] verdade que no médium homogêneo das ciências matemáticas puras a gente pode realizar extrapolações de maneira quase ilimitada, porém, desde que se trate do ser, antes de toda extrapolação é preciso se interrogar se o processo a ser tratado é tal no seu próprio ser que a extrapolação seria capaz de esclarecer precisamente suas tendências reais." (LUKÁCS, 2009, p. 51).

9 A acumulação desenfreada "[...] incide sobre ativos fictícios e se impulsiona no fato de que se apoia hoje sobre a informática e as matemáticas de tipo particular às quais as finanças recorrem. Isso contribui ainda para aumentar a ilusão de o dinheiro engendra o dinheiro graças ao milagre das «inovações financeiras»." (CHESNAIS, 2010, 39).

10 Esse neointervencionismo, com globalização e democratização da governança, tem duas componentes ideológicas, a saber: a $1^{\text {a }}$ é explicitamente liberal, universalizando a divisa republicana "[...] da liberdade, da igualdade e da fraternidade" (AGLIETTA; BERREBI, 2007, p. 420); a $2^{\mathrm{a}}$ é implicitamente conservadora, universalizando a divisa positivista "da ordem e do progresso [...]" (FARIAS, 2000, p. 90).

\section{Flávio Bezerra de Farias}

Economista

Doutorado de Terceiro Ciclo em Economia e Gestão pela Universidade de Amiens, Doutorado de Estado em Economia pela Universidade Paris-Nord.

Professor da Universidade Federal do Maranhão (UFMA) E-mail: flaviobezerradefarias@gmail.com

\section{Universidade Federal do Maranhão - UFMA}

Cidade Universitária do Bacanga

Avenida dos Portugueses, 1966-Bacanga

85.085-580- São Luís- Ma 